\title{
APPENDICITIS IN THE ELDERLY PATIENT WITH MULTIPLE CO-MORBID CONDITIONS: CASE REPORT
}

\author{
Rayamajhi $A J^{1^{*}}$, Paudel $P^{2}$, Yadav $R K^{3}$, Paudel $S C^{2}$, Dhungel $B K^{2}$, Byanjankar $B^{2}$, Pandit $R^{2}$
}

\section{Affiliation}

1. Associate Professor, Department of Anesthesiology, Critical Care \& Pain Medicine, Civil Service Hospital, Nepal

2. Registrar, Department of Anesthesiology, Critical Care \& Pain Medicine, Civil Service Hospital, Nepal

3. Assistant Professor NAMS/Department of Pediatric Anesthesia, Kantichildren Hospital

\section{ARTICLE INFO}

Article History

Received : 24 July, 2018

Accepted : 25 March, 2019

Published : 30 May, 2019

(C) Authors retain copyright and grant the journal right of first publication with the work simultaneously licensed under Creative Commons Attribution License CC - BY 4.0 that allows others to share the work with an acknowledgment of the work's authorship and initial publication in this journal.

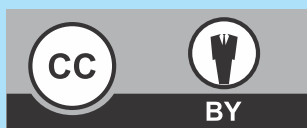

\section{CR 27}

DOI: http://dx.doi.org/10.3126/bjhs.v4i2.25463

\section{* Corresponding Author \\ Dr Anuj Jung Rayamajhi \\ Associate Professor \\ Department of Anesthesiology,}

Critical Care \& Pain Medicine, Civil Service Hospital, Nepal

Email ID : anujrayamajhi@gmail.com

ORCID ID: http://orcid.org/0000-0002-0138-6502

\section{Citation}

Rayamajhi AJ, Paudel P, Yadav RK, Paudel SC, Dhungel BK, Byanjankar B,

\section{ABSTRACT}

Acute appendicitis is commonly encountered surgical emergency worldwide. ${ }^{1}$ Although, it is commonly found in young and middle aged groups, the incidence of the diseases in geriatric age group is very rare and possesses a great challenge to safe technique of anesthesia due to co-existing comorbid conditions and medications used. ${ }^{2}$ Geriatric population are more susceptible to complications of appendicitis. ${ }^{3}$ This is a case report of 82 years old male patient, presented with appendicular perforation with localized abscess formation in a septic state with multiple comorbid condition. Routinely performed Spinal and general anaesthesia adds further challenge in management of this patient during and after surgery. Therefore, we performed the case in regional nerve block; paravertebral, ilioinguinal- iliohypogastric (ILIH) and coeliac plexus block and sedation.

\section{KEYWORDS}

Acute appendicitis, peripheral nerve block, coeliac plexus, paravertebral 


\section{CASE REPORT}

This is a referral case of acute appendicitis of 82 years old male from other centre for regional anesthesia. He is a known case of diabetes II, hypertension, chronic obstructive airway disease on domiciliary oxygen and left frontal lobe gliosis. He was under tab. leveteracetam $500 \mathrm{mg} \mathrm{BD}$, Tab rosuvastatin $10 \mathrm{mg} O D$, tab. amlodipine $5 \mathrm{mg} /$ losartan $50 \mathrm{mg}$ OD,Tab. clopidrogel $75 \mathrm{mg}$ OD, Tab. aspirin $75 \mathrm{mg}$ OD, tab metformin $500 \mathrm{mg} \mathrm{BD}, \mathrm{R} / \mathrm{C}$ budenoside/formetrol BD.

Lab investigations showed total count -16500 (N80,L15, E3, $\mathrm{M} 1, \mathrm{~B} 1)$ cells/cumm, haemoglobin $-17 \mathrm{gm} / \mathrm{dl}$, platelets 80,000 cell/cumm, prothrombin time -21sec and international normalization ration 2.5 , blood group A positive.

Serum biochemistry showed: sodium $140 \mathrm{meq} / \mathrm{l}$, potassium $4.9 \mathrm{meq} / \mathrm{l}$, random blood sugar $-200 \mathrm{mg} / \mathrm{dl}$, urea- $55 \mathrm{mg} / \mathrm{dl}$, creatinine- $1.5 \mathrm{mg} / \mathrm{dl}$ chest $X$-ray showed hyper-inflated lung fields with diffuse opacities. ECG was unremarkable.

Ultrasonographic study of abdomen showed mild fatty changes in liver, right renal paraplevic cyst, ill defined collection in right iliac fossa with probe tenderness was noted. Appendix was not visualized.

Risks and benefits of the regional anesthesia and procedure were explained to the patient and his relatives and written consent was obtained for the procedure.

\section{METHOD}

On arrival in the operation theatre, standard ASA monitoring was done. Baseline values were blood pressure: 100/ $70 \mathrm{mmHg}, \mathrm{PR}-100 / \mathrm{min}, \mathrm{SpO} 2-53 \%$ in room air and $90 \%$ with oxygen supplementation at $6 \mathrm{lt} / \mathrm{min}$ via facemask in semi recumbent position.

Patient was sedated with midazolam of $0.5 \mathrm{mg}$ and fentanyl $25 \mathrm{mcg}$. Patient was kept in left lateral position. Under all aseptic precaution precaution 26 gauge spinal needle and color doppler was used in all procedures considering risk of bleeding.

\section{Paravertebral block}

Linear probe was used for paravertebral block. Scanning was done from midline identifying spinous process of $\mathrm{T} 9$ thoracic vertebrae. Probe was moved laterally and caudally to identify transverse process and intercostal muscle hence paravertebral space. Needle was then introduced in inplane technique. $0.25 \%$ bupivacaine $25 \mathrm{ml}$ was then injected in space and drug spread was confirmed by real time imaging ( Fig.1).

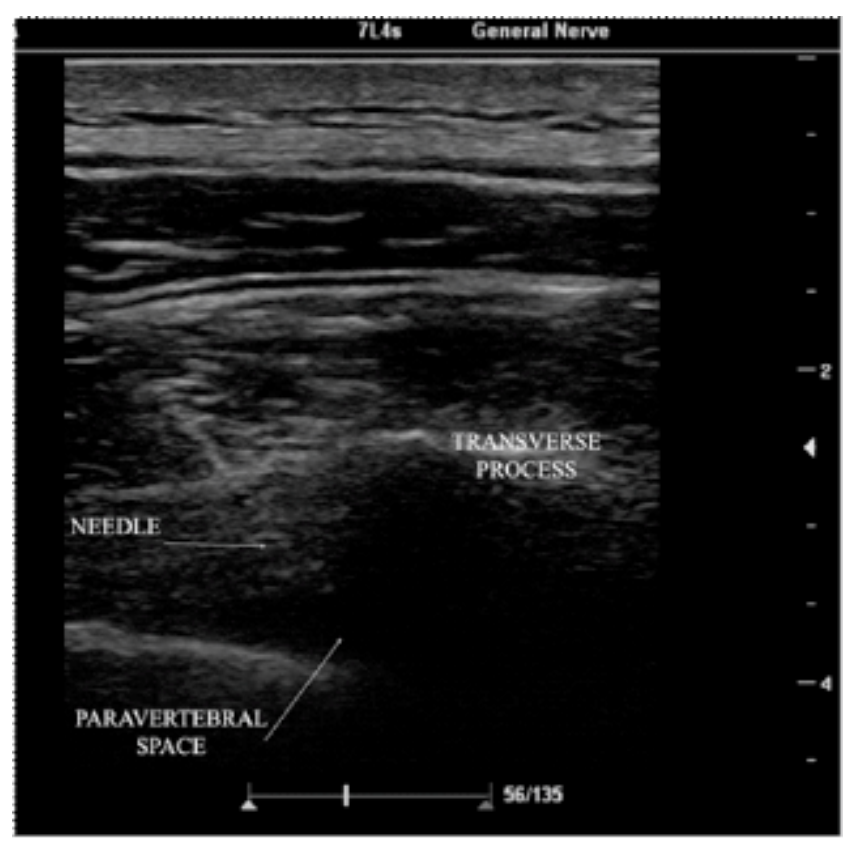

Figure 1: Showing needle insertion and LA spread in Paravertebral space.

\section{Coeliac plexus:}

Coeliac plexus was approached from posterior side using convex probe ultrasound.

First lumbar vertebrae and upper pole of kidney were identified in transverse view (Fig.2) [4,5].

View was optimized such that kidney and only vertebral body were identified. Out of plane technique was used to reach anterolateral side of vertebrae in real time. Adequate depth was confirmed by depth measured in Ultrasound . Before injecting the drug, $300 \mathrm{ml}$ of plasmalyte was administered to prevent hypotension. $15 \mathrm{ml}$ of $0.5 \%$ lignocaine with adrenaline was injected and probe placed in epigastrium to confirm drug spread (Fig.3). Same process was done for other side side.

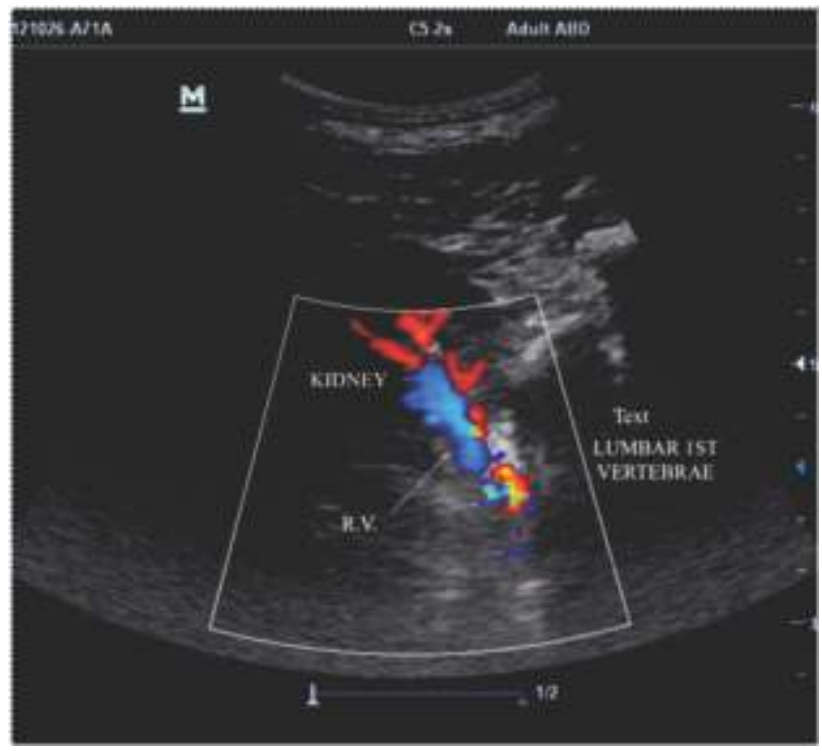

Figure 2: Showing renal Vessels (RV) and Lumbar 1st vertebrae 


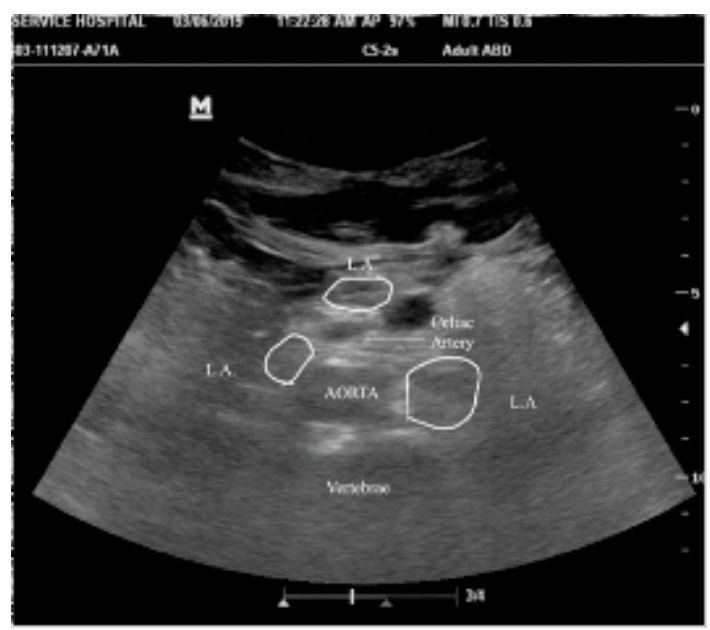

Figure 3: Anterior view of drug spread around aorta and celiac artery

\section{Ilioinguinal - Iliohypogastric Nerve block}

Linear probe was used to identify iliac creast and abdominal muscles.10 mlof 0.25\% Bupivacaine was injected in in plane technique after identifying nerves.Adequacy of the block was checked by performing pinprick test after achieving anesthesia in required dermatome (T8-L1 dermatome level) then only surgery was proceded. Dexmeditomidine was started in titrated maintenance dose. Further $25 \mathrm{mcg}$ of fentanyl was used 2 mins before incision. Grid iron incision was given and surgery carried out. Intra operative finding was appendicular lump with localized abscess. Duration of surgery was 45 mins and lumpectomy was done. Dexmeditomidine was stopped during closure of abdominal wall muscle. Patent had the Ramsay sedation score of 2 at the end of surgery. Patient was kept in surgical intensive care unit for 2 days for close monitoring. Patient was kept in ward for next 3 days then discharged on oral antibiotics and continuation of his regular medicines.

\section{DISCUSSION}

In the recent years, ultrasound guided peripheral nerve block (PNB) is gaining popularity for analgesia and anesthesia. Being resource limited country practice of PNB for anesthesia is more common in our region. Patient undergoing emergency surgery with co-morbid condition like COAD on domiciliary oxygen can develop several postoperative complications like delayed recovery from general anesthesia, post operative lung atelectasis, difficult weaning.

Though all procedures and surgery itself carry high risk of bleeding in this case. Neuroaxial intervention carries highest risk and devastating complication ${ }^{6}$ in patient with deranged INR of 2.5 \& hence avoided. Use of small gauge $26 \mathrm{G}$ spinal needle under real time guidance with color doppler can identify vessels thus decrease risk of bleeding and will be an excellent alternative ${ }^{7}$.

Toal of $35 \mathrm{ml} 0.25 \%$ bupivaicne plane was used for the procedure which is within recommend safe limit. However there might be altered pharmacodynamics in geriatric age groups and have to act judicially as its not possible to get report of expected changes in absorption, metabolism and elimination and act accordingly.

Maximum dose of local anesthetics presented in textbooks or companies are not evidence based.

Toxicity depends on peak concentration of drugs in blood which is multifactorial like injection near artery, using higher concentration of drugs, presence of adipose tissues at that site, lipophilic nature of drugs, size of needle used, use of adrenaline along with local; apart from volume and pharmacodynamics ${ }^{7}$. Toxic dose should be revised as per site and technique specific.

Similar plasma concentrations of lidocaine are achieved after $300 \mathrm{mg}$ in intercostal nerveblock, after $500 \mathrm{mg}$ in epidural block, after $600 \mathrm{mg}$ in brachial plexus block, and after 1,000 mg in subcutaneous infiltration of the skin of the legs demanding site and techniques specific recommendation for maximum safety dose ${ }^{7}$.

Celiac plexus block was first used in 1946 by Pitkin as a blind technique for surgical anesthesia and later gained popularity as a choice of analgesic for pancreatic carcinoma and abdominal visceral pain. Various approaches transintervetrebral discal, transcrural, transaortic, posterior (retrocural) $\&$ anterior approaches has been described ${ }^{10}$. All of which techniques identifies L1 or T12 vertebrae as a bony landmark. Similiary renal vessels which arise form L1 \& taken as landmark in USG. Furthermore real time imaging provides safety not injuring kidney, small ,large vessels \& real time drug spread can be possible to visualize with USG only adding further safety over C-arm technique.

Role of regional anesthesia in abdominal surgeries peripheral nerve block is limited to post operative analgesia worldwide, however when performed by routinely practicing anesthesiology it is very safe compared to any other techniques and can be used as an anesthesia technique with high success rate ${ }^{5}$.

\section{CONCLUSION}

PNB with sedation is an excellent technique for appendectomy surgeries in high risk and geriatric age group and pave a path to be be used routinely in future in these group.

\section{CONFLICT OF INTEREST}

None

\section{ACKNOWLEDGEMENTS}

None

\section{FINANCIAL DISCLOSURE}

None 


\section{REFERENCES}

1. Anderson M, Ruber M, Ekerfelt C, Hallgren HB, Olaison et al. Can new inflammatory markers improve the diagnosis of acute appendicitis ? World J Surg 201438:2777-2783

2. Lenox PH, Vaghadia H, Hendorson C, Martil L Mitchell GW. Small low dose selective spinal anesthesia for short duration outpatient laparoscopy : Recovery characteristics compared with desflurane anesthesia. Anesth Analg $200294: 346: 350$

3. Temple C, Huchcroft S, Temple W. The natural history of appendicitis in adults and adolescents. Annals of internal Medicine. 1995141 (7) : 537-546

4. Coeliac Plexus Blockade And Neurolysis: An Overview: Indian J. Anaesth. 2006(53) : 169-177

5. Bhattarai PR, Rayamajhi AJ, Yadav RK, Paudel SCP, Pangeni A, Byanjankar B, Pandit A. Comparison of ultrasound-guided abdominal nerve blocks and subarachnoid block as an anesthetic technique for appendectomy: Jsan 2017; 4 (1)
6. Regional anaesthesia and patients with abnormalities of coagulation The Association of Anaesthetists of Great Britain \& Ireland The Obstetric Anaesthetists' AssociationRegional Anaesthesia UK: Anaesthesia 2013, 68, 966-972

7. Safety of the paravertebral block in patients ineligible for epidural block undergoing pulmonary resection: General Thoracic and Cardiovascular surgery. December 2012, Volume 60, Issue 12, pp 811-814

8. Maximum Recommended Doses of Local Anesthetics: A Multifactorial Concept :Regional Anesthesia and Pain Medicine, Vol 29, No 6. (November-December), 2004: pp 564-57

9. Kappis, M. (1914) Erfahrungen Mit Localanasthesie bie bauchoperationen. Vehr Dtsch Gesellsch Chir, 43, 87-89

10. Celiac Plexus Block and Neurolysis: A Review: Gastrointest Endosc Clin N Am. 2018 Oct; 28(4):579-586. 